\title{
A HISTÓRIA DA ARTE COMO SABER DOS SINTOMAS
}

\author{
Everton de Oliveira Moraes ${ }^{1}$
}

\begin{abstract}
DIDI-HUBERMAN, Georges. Diante da imagem: questão colocada aos fins de uma história da arte. Trad. Paulo Neves. São Paulo: Editora 34, 2013.
\end{abstract}

Com quase 25 anos de atraso e depois de uma série de traduções de obras e artigos de Georges Didi-Huberman para o português, é lançado no Brasil Diante da imagem (1990), um de seus primeiros e mais importantes títulos. O livro formula, de maneira mais bem acabada, algumas questões que vinham se impondo ao autor desde suas primeiras publicações, como L'Invention de l'hystérie, em que o imaginário sobre as patologias mentais é analisado como parte constitutiva da invenção do objeto histeria e do saber psicanalítico; e $A$ pintura encarnada, na qual busca forjar uma análise das imagens para além de sua pura visibilidade ou abordar o caráter fantasmático das obras de arte. Agora, em Diante da imagem, alguns dos resultados dessas primeiras pesquisas aparecem no questionamento do sujeito soberano do conhecimento na História da Arte ou na elaboração do conceito de visualidade.

No livro, Didi-Huberman busca pensar com Freud as imagens da arte, isto é, se apropriar das análises das imagens dos sonhos elaboradas pelo psicanalista, mas aplicando-as às imagens da arte. Trata-se de problematizar uma certa "retórica da certeza" e uma submissão da arte a certos "fins" bem como suas implicações teóricas e metodológicas - que atravessam a História da Arte de Vasari a Panofsky e outros adeptos contemporâneos da disciplina, fazendo de sua narrativa aquele conhecido "romance familiar". Se durante muito tempo a disciplina visou tornar a arte uma expressão da superioridade dos valores universais do humanismo, subsistiria nos seus

1 Doutorando em História na Universidade Federal do Paraná. 
historiadores atuais, ainda que seu discurso seja muito mais complexo e sofisticado, a ideia de um sujeito transcendental, capaz de apaziguar os conflitos e conter o "infinito desdobramento das imagens singulares" ( $p$. 171) utilizando a mesma ferramenta: a "representação".

O filósofo parte das imagens cristãs para problematizar essas certezas, o que interessa não é tanto fazer uma história dessas imagens, nem situá-las em uma linha do tempo do desenvolvimento da história da arte. Tampouco fazer, a partir de Freud, uma clínica das imagens da arte. Mas antes, utilizar um paradigma crítico freudiano para contestar o "tom de certeza" adotado por muitos historiadores da arte: apontar que as imagens cristãs - algumas delas desprezadas pela história oficial da arte - podem ser indícios para pensar um outro modo de saber histórico da arte; ressituar o historiador em relação ao seu objeto, "reconsiderar o estatuto mesmo desse objeto de saber" para pensar o que ganhamos e o que perdemos com esse modo de proceder.

Muito cara a Didi-Huberman é a análise da cesura e do conflito entre visível (o domínio da representação, da imitação e da significação) e visual (a apresentação, a deformação, o novo), que ele afirma remontar às imagens cristãs da Idade Média. Para ele, teria sido justamente a moderna disciplina da História da Arte e sua racionalidade a maior responsável pela tentativa de apaziguar e anular essa cesura, obliterando o visual e privilegiando o visível. Daí a dificuldade de pensar a visualidade: nesse exercício, o pensamento teria que se esforçar para sair daquilo que aparece como óbvio, isto é, a visibilidade.

Não que o filósofo acredite em um "retorno" ao passado ou na busca de respostas antigas para problemas contemporâneos. O que importa é perscrutar possibilidades de pensar diferentemente a História da Arte. Tarefa para a qual a indagação a respeito de um tempo em que o "tom de certeza" da interpretação das obras de arte ainda não havia constituído sua tirania parece ser fundamental. Trata-se de uma Idade Média em que Vasari e Alberti ainda não haviam esquadrinhado e classificado a cultura visual ocidental, subjugando-a aos domínios de um saber humanista.

Tudo começa, em suma, com um "não saber". Uma imagem, uma visualidade nos atinge, se impõe e passa a nos perturbar, insiste em nos perseguir, sem que nem mesmo saibamos o que nela nos perturba, do que se trata ou o que ela pode significar. É para enfrentar esse "não saber", esse 
afeto, e produzir um certo saber a partir dele que o historiador da arte se põe a trabalhar.

Desde Vasari, a história da arte enquanto disciplina acadêmica (crítica que se estende também a parte da historiografia) não teria cessado de tentar domesticar seus objetos, as imagens, integrando-as "ao esquema convencional do domínio do visível" (p. 39), isto é, explicando suas contradições e seus paradoxos por meio de modelos esquemáticos, que reduzem a multiplicidade da imagem ao que já é bem conhecido e inventariado. Nesse percurso, a disciplina dá conta de inserir as obras de arte em uma história (narrativa histórica), mas não de apresentar sua irredutível diferença com relação a ela, suas rasgaduras, suas pontas. Assim, para Didi-Huberman, uma das tarefas mais importantes da história da arte hoje é pensar as imagens enquanto "parte construída", mas também enquanto "parte maldita", pensar a historicidade (as narrativas históricas) juntamente "com aquilo que pode arruiná-la" (p. 241).

Nos últimos séculos, no ocidente, especialmente a partir de Kant, a ideia de saber teria sido cada vez mais associada à noção de conhecimento objetivo, distanciado. Os saberes que surgem em toda parte passaram a só ganhar legitimidade institucional se aderissem a uma certa epistemologização e disciplinarização, isto é, se delimitassem muito bem um conjunto de objetos de estudo, demarcassem precisamente as posições de sujeito de seus participantes, criassem um conjunto de conceitos analíticos e uma discursividade própria, uma forma de narrar particular, regras capazes de regular a construção de enunciados, frases e sentidos.

Para um saber moderno de pretensões cientificistas é fundamental que haja um objeto bem delimitado, um certo número de coisas sobre as quais as descrições, as interpretações, as análises devem recair. Mesmo nas chamadas ciências humanas, que se pretendem menos rígidas e mais abertas às contingências do humano que tomam por objeto, durante muito tempo se clamou pela necessidade de uma objetividade que pudesse dar conta de eliminar o subjetivismo, as interpretações parciais e interessadas. Essa objetividade nada mais é do que o imperativo de manter-se senhor de si mesmo e de seu objeto de estudo: controlar sua própria subjetividade, impor-se um método, para que esta não interfira na análise do objeto e, portanto, dominar soberanamente este último, explicá-lo de maneira inequívoca. Governar a si mesmo para dominar o objeto. Assim nasce o sujeito moderno do saber. 
É esta relação de poder, esta dominação em relação ao objeto, que é problematizada por uma série de discursos no século XX (das vanguardas artísticas até a história, passando pelas ciências sociais e pela filosofia). E é uma problematização desse gênero que Didi-Huberman utiliza para fazer uma crítica da História da Arte enquanto disciplina acadêmica. Nas suas palavras, trata-se de "seguir os meandros de um problema que diz respeito aos poderes de invenção de um discurso sobre o objeto que ele pretende descrever" (p. 115).

É, portanto, contra o sujeito soberano do saber que Didi-Huberman evoca a figura de um historiador da arte afetado, incomodado, perseguido e olhado pelas imagens que analisa. Um sujeito que não possui e não domina mais seu objeto, que parte desse "não saber" para construir um saber capaz de afetar o seu presente, criticá-lo, arruinar nele aquilo que parecia imutável e indestrutível. Neste ponto, Didi-Huberman parece concordar com Roberto Esposito, quando este afirma que "o único modo de não desembocar na possessão do objeto pelo sujeito é questionando os limites constitutivos do sujeito, isto é, diminuindo ao máximo o sujeito".

$\mathrm{O}$ encontro do historiador da arte com a obra ou a imagem é o acontecimento que o incita, o motiva ou até o coage a investigar, a pesquisar e a escrever. Esse encontro é o "não saber", a partir do qual o saber pode ser produzido. Esse encontro faz emergir "conflitos" que, mais do que apaziguar, interessa enfrentar. Podem mesmo ser chamados de "sintomas", para usar o termo de Didi-Huberman. "Um sintoma aparece, um sintoma sobrevém, interrompe o curso normal das coisas segundo uma lei - tão soberana quanto subterrânea - que resiste à observação banal. O que a imagem-sintoma interrompe não é outra coisa que o curso normal da representação". Encontros aparentemente banais podem tornar-se matérias-primas para uma investigação pelas forças que mobilizam. Como a observação de uma "brancura", no afresco de Fra Angelico, que não corresponde aos códigos pictóricos de representação da época. A busca para entender o lugar dessa "brancura" na pintura em questão é que leva o filósofo a perceber que esta não diz respeito ao domínio da visualidade representativa, mas corresponde a um desejo de mimese por apresentação. Como se estivesse em jogo, para este monge medieval, não a representação da Anunciação, mas a evocação da força da Anunciação ela mesma.

O sujeito (produtor) desse saber não é mais, portanto, aquele sujeito 
soberano, senhor do conhecimento, analista científico que domina seu objeto impondo a ele a narrativa de um texto acadêmico ou de uma pintura realista que deveria expressar fielmente a atmosfera da situação retratada. Não é mais possível tomar esse distanciamento quando se admite que o que se investiga não é um objeto distante no tempo ou no espaço (uma civilização morta, um regime político do passado ou uma cultura distante), mas um evento pessoal, um encontro vivido e sentido pelo próprio sujeito do saber.

Trata-se de um sujeito afetado pelo objeto do qual fala, de modo que a própria oposição entre sujeito e objeto pode ser questionada. Este sujeito já não tem mais certeza sobre quem exatamente ele é, sobre como proceder com relação ao objeto. Ele sabe que deve achar seu caminho em meio aos conflitos e possibilidades da atualidade. Não se trata, enfim, de um saber em que as relações entre sujeito e objetos estariam bem delimitadas e definidas de uma vez por todas.

Em um belo parágrafo em que descreve a relação do historiador com a imagem de arte, Didi-Huberman opõe a metáfora panofskiana, do homem que polidamente vemos tirando o chapéu para nós, à descrição freudiana do sonho caótico e paradoxal:

Não se olhará, portanto, uma imagem da arte como se olha um velho conhecido que cruzamos na rua e que, já identificado, levantaria polidamente seu chapéu para nós. No entanto, é o que muitos historiadores, desde Vasari, fizeram, fazem ou fingem fazer. Eles se colocam diante da imagem como diante do retrato reconfortante de alguém cujo nome já gostariam de conhecer, e do qual exigem implicitamente a "boa figura", isto é, o mínimo de decoro figurativo que um chapéu corretamente colocado na cabeça sugere. Mas o mundo das imagens jamais se constituiu com a única finalidade de fazer boa figura para uma história ou um saber a ser constituído sobre elas. Muitas imagens - mesmo aquelas com as quais nos acreditamos familiarizados - agem como enigma cujo exemplo Freud introduziu a propósito do trabalho da figurabilidade: elas correm despenteadas, o chapéu voando no ar, às vezes correm mesmo sem cabeça... pois tal é o trabalho do sintoma que muitas vezes chega a decapitar a Ideia ou a simples razão a se fazer de uma imagem (p. 239).

Sonhar, inventar, imaginar. Parecem ser traços constitutivos da "metodologia" de um saber dos sintomas. Como se para lidar com os encontros e as contingências do acontecimento fosse necessário usar a imaginação. $\mathrm{O}$ 
método de Didi-Huberman não é baseado na classificação, mas nessa imaginação, entendendo-a não como mero devaneio, criação mental desregrada, mas como atitude que tem seus procedimentos. Um processo de criação de imagens, que trazem em um só golpe, juntos, passado e presente, atual e inatual, com uma força capaz de romper com um discurso de saber que impõe um domínio sobre seu objeto (sobre aquilo que nele é "não saber"), dando-lhe um fim, uma direção, fechando-o para suas virtualidades. Mas que também não teme a superinterpretação e não cai na armadilha "positivista" que consiste em acreditar que se pode deixar o passado falar por si mesmo. Imaginar, antes de tudo, inventar a partir deste passado que lhe afeta.

Abrir-se sempre para esse "não saber" caótico, desorganizado, que nos perturba e nos rasga, nos amplia possibilidades de pensar, parece ser uma tarefa fundamental para os historiadores da imagem e da arte, segundo Didi-Huberman. Os encontros do historiador com as imagens que toma por objeto se dão naquele "instante do perigo" do qual Walter Benjamin falava, em meio a uma atmosfera de "não saber", que rechaça qualquer "tom de certeza". Pois esses objetos que o historiador da arte busca explicar são eles mesmos forças, expressão de forças, aparecimento de forças que não cessam de atravessá-lo.

Recebido em 10 de maio de 2014. Aprovado em 06 de novembro de 2014. 